\title{
Tuberculosis prevalence among university freshmen in Zhengzhou, China, during 2004-2013
}

\author{
Yu-Hong Wang ${ }^{1, \dagger}$, Ye Tian ${ }^{1,2, t^{*}}$, Jin-Xin Gao ${ }^{3,4,}$, Chao-Kuan Lei ${ }^{5}$, Yan-Wen Liu ${ }^{6}$, \\ Zhong-Min Han ${ }^{1}$, Hua Xing ${ }^{1}$, Can Yan ${ }^{1}$, Le Zhou ${ }^{7, *}$
}

1. Department of Medical Technology and Engineering, Zhengzhou Railway Vocational and Technical College, Zhengzhou, Henan, 451460, China.

2. College of Chemistry \& Pharmacy, Northwest A\&F University, Yangling, Shaanxi, 712100, China.

3. Department of Food Cooking and Health, Henan Polytechnic, Zhengzhou, Henan, 450046, China.

4. College of Enology, Northwest A\&F University, Yangling, Shaanxi, 712100, China.

5. Division of Tuberculosis, The Sixth People's Hospital of Zhengzhou, Henan, China.

6. College Hospital, Zhengzhou Railway Vocational and Technical College, Zhengzhou, Henan, China.

7. College of Chemistry \& Pharmacy, Northwest A\&F University, Yangling, Shaanxi, 712100, China.

† These authors contributed equally to this work.

\section{Abstract}

Background: Tuberculosis (TB) is a major public health concern worldwide, and spreads more easily in densely populated areas such as school campuses.

Objectives: The aim of this study was to determine the prevalence of positive TB skin tests among freshmen, i.e. newly-enrolled college students, in Zhengzhou City, China.

Methods: We reviewed the data of purified protein derivative (PPD) skin tests in 656,212 freshmen in 2004-2013.

Results: A positive test showed a diameter of swelling $\geq 5 \mathrm{~mm}$. The PPD positive rate was $40.69 \%$, with a prevalence of 146.29 per 100,000. During the 10-year study period, the rate of students with positive PPD test increased from $34.19 \%$ in 2004 to $40.69 \%$ in 2013. The positive PPD rate was significantly higher in males than in females (41.68 \% vs 39.61 \%, P<0.0001), and in rural compared with urban areas $(42.04 \%$ vs $38.03 \%, \mathrm{P}<0.0001)$.

Conclusion: These findings indicated a high prevalence of PPD positivity among participants during the study period, with an increasing trend. Therefore, this population needs to be targeted by TB prevention and control programs.

Keywords: Tuberculosis; PPD test; freshmen; positive rate; prevalence.

DOI: https://dx.doi.org/10.4314/ahs.v18i4.32

Cite as: Wang Y-H, Tian Y, Gao J-X, Lei C-K, Liu Y-W, Han Z-M, Xing H, Yan C, Zhou L. Tuberculosis prevalence among university freshmen in Zhengzhou, China, during 2004-2013. Afri Health Sci. 2018;18(4): 1109-1116. bttps://dx.doi.org/10.4314/ahs.v18i4.32

\section{*Corresponding author:}

Ye Tian,

Zhengzhou Railway Vocational and Technical College,

Zhengzhou, Henan, 451460, China; College of Chemistry

\& Pharmacy, Northwest A\&F University, Yangling,

Shaanxi, 712100, China

E-mail: tianye@zzrvtc.edu.cn (Y. Tian);

Or

Le Zhou,

College of Chemistry \& Pharmacy, Northwest A\&F

University, Yangling, Shaanxi, 712100, China

Tel: +8613633716826 (Y. Tian);

+860371-60867321 (office)

Email: zhoulechem@nwsuaf.edu.cn (L. Zhou)

\section{Introduction}

Where there are humans, Mycobacterium tuberculosis (MTB) seems to be present as well. Tuberculosis (TB) has been a powerful deterrent to worldwide health since ancient times, and the main cause of death due to bacterial infection $^{1}$. Currently, TB is the seventh most common disease worldwide, a trend projected to continue until $2020^{2}$. According to yearly WHO global TB reports since $1997^{2-8}$, statistical results from 1990 to 2015 showed that TB related deaths declined from 2 to 1.4 million, but new cases are on the rise, from 8.47 to 10.4 million. TB remained one of the top 10 causes of death worldwide in $2015^{8}$. Indeed, over the past decade, reports on the tuberculosis epidemic have originated from many African and Asian

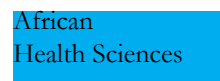

(C) 2018 Wang et al. Licensee African Health Sciences. This is an Open Access article distributed under the terms of the Creative commons Attribution License (https://creativecommons.org/licenses/BY/4.0), which permits unrestricted use, distribution, and reproduction in any medium, provided the original work is properly cited. 
countries such as Vietnam, Philippines, Ethiopia, Korea, Japan, China, India, et al. ${ }^{9-20}$

However, not enough precise data are available to determine whether the back-and-forth trend will re-emerge. Worldwide, TB incidence has declined by only $1.5 \%$ from 2014 to $2015 .^{21}$ This needs to increase to a $4-5 \%$ annual decline by 2020 to reach the first milestone of the End TB Strategy ${ }^{8}$. TB was a leading cause of adult mortality in low- and middle-income countries, ranking third after HIV and ischemic heart disease among individuals aged 15-59 years in 2001 ${ }^{22}$. Besides the suffering caused by TB in humans, the monetary burden was estimated to have exceeded US $\$ 56$ billion, up from US $\$ 3.5$ billion in 2006 to US\$ 6.7 billion in 2015. This is in part due to the WHO Millennium Development Goals (MDG) and Stop TB Partnership targets for 2015, which aim to halt and reverse TB incidence, halve prevalence and mortality rates compared to 1990 levels, detect at least $70 \%$ of infectious cases, and successfully treat $85 \%$ of the infectious cases detected ${ }^{23}$. The more important long-term elimination target set for 2050 will not be met with current strategies and tools. Global actions and investments fall far short of those needed to end the global TB epidemic ${ }^{8}$. Several key challenges persist, including unaffordable sufficient quality services to vulnerable people, multidrug-resistant M. tuberculosis strains, underlying social determinants in the community, and obsolete and inadequate technologies for diagnosis, treatment, and prevention ${ }^{24}$. China had the second largest number of new TB cases after India in 2004-2013 $3^{7,25}$. The Fifth National Tuberculosis Epidemiological Survey (FNTES) in 2010 showed declined TB prevalence in $\mathrm{China}^{26}$. However, specific groups appear to be at higher risks, including freshmen from TB epidemic backgrounds, underdeveloped regions, and even some unexpected places such as college and university campuses. This high incidence could lead to widespread outbreaks if ignored. The objective of the present study was to appraise the TB epidemic in colleges and universities, exploring effective measures for disease prevention and treatment. Our findings suggest that more focus of public health is needed to prevent the outbreak of infectious diseases in colleges.

\section{Materials and methods \\ Study participants}

There were 656,212 freshmen attending 30 colleges and universities in Zhengzhou, China, in 2004-2013. This study was conducted in accordance with the ethical standards of the Helsinki Declaration, and approved by the Medical Ethics Committee of the Sixth People's Hospital of Zhengzhou (document number 2011HNIN003). In accordance with China's national conditions, the main auxiliary method of tuberculosis diagnosis for freshmen was PPD screening. All participants provided verbal consent, and permission was obtained from local authorities.

\section{Tuberculosis testing}

Study participants received $0.1 \mathrm{ml}$ (5 IU) PPD (1:2000) subcutaneously in the inner forearm. Forty-eight to 72 hours after injection, the site was evaluated by a physician. The reaction was considered to be negative, weakly positive, moderately positive, and strongly positive with greatest swelling diameters of $<5 \mathrm{~mm}, 5-9 \mathrm{~mm}, 10-19$ $\mathrm{mm}$ and $\geq 20 \mathrm{~mm}$ (or $<20 \mathrm{~mm}$ with blisters, necrosis or lymphatitis), respectively ${ }^{27}$.

\section{TB treatment}

Students with a strongly positive PPD test result underwent chest X-ray examination. In case of lung shadow discovery upon imaging, the students were referred to the TB Control Institute, Zhengzhou City, for further examination. Students with a strongly positive PPD test result as well as those with undetermined active TB status were administered preventive medication after written informed consent. The two treatment regimens used were isoniazid at $0.3 \mathrm{~g} /$ day for 6 months or Rifapentine and isoniazid combination at $0.6 \mathrm{~g}$ twice weekly for 3 months $^{28}$. Confirmed active TB cases were transferred to local TB prevention and control institutions for out-patient or inpatient treatment, and instructed to stay at home for 1 to 3 months. All patients underwent treatment by TB prevention and control institutions until disappearance of clinical symptoms, demonstrated by three consecutive negative sputum smear examinations for acid-fast bacilli (AFB) and lung imaging showing no fibrosis or sclerosis. High prevalence of persistent cough and AFB-positive sputum smears required further exploration. Patients with clinical 
cure- and restoration class certificates issued by respective TB prevention and control institutions could return to school. The College Hospital Preventive Care Section archived the information of each patient and tracked patient management until recovery.

\section{Statistical analysis}

Statistical analyses were performed with SPSS, version 17.0 (SPSS Inc., Chicago, IL, USA). P<0.05 was considered statistically significant. Multiple groups were compared with the $\chi^{2}$ test.

\section{Results}

Of the 656,212 students administered the PPD test, $221,292(33.72 \%)$ and 434,920 (66.28\%) lived in urban and rural areas, respectively; 341,186 (51.99\%) were males, with $315.026(48.01 \%)$ females. A total of 266,992 $(40.69 \%)$ and $44,563(6.79 \%)$ were positive and strongly positive, respectively. There were 960 diagnosed TB cases, indicating an incidence of 146.29/100,000. Over the 10-year study period, the PPD positive rate and TB prevalence increased annually (Fig 1). A comparison of annual weakly positive rates showed a statistically significant difference $(\mathrm{P}<0.0001)$; similar results were obtained for moderately positive PPD, strongly positive PPD, and total positive PPD cases, as well as TB prevalence $(\mathrm{P}<$ 0.0001). The total positive and strongly positive rates, as well as prevalence in boys were significantly higher than the values obtained for girls, and significantly higher in rural than urban areas $(\mathrm{P}<0.0001)$ (Table 1).

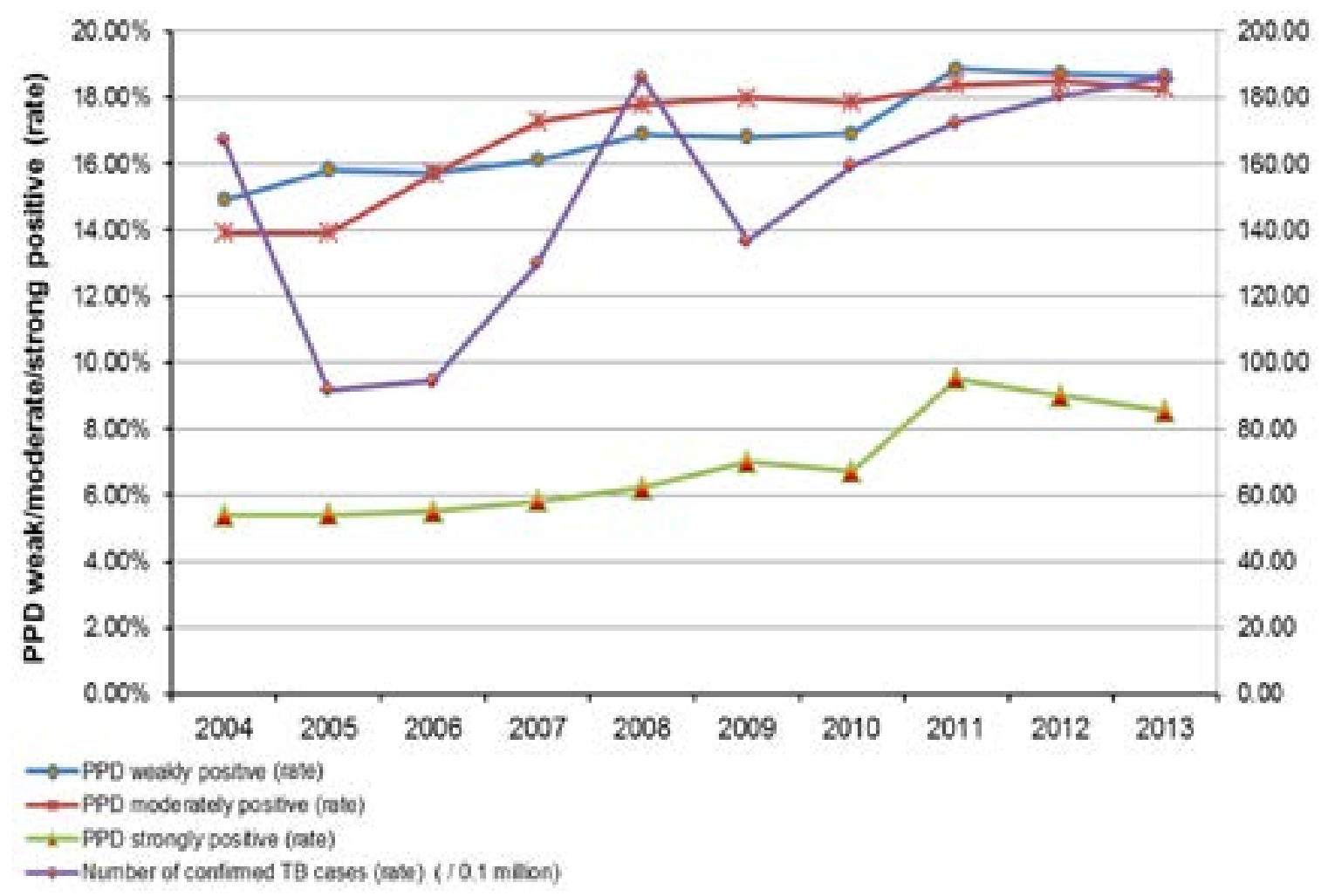

Figure 1 Trend of PPD test results of 2004-2013 freshmen in Zhengzhou City (cases). 
Table 1 PPD test results by year

\begin{tabular}{|c|c|c|c|c|c|c|c|c|c|c|c|c|}
\hline \multirow[t]{3}{*}{ Year } & \multirow{3}{*}{$\begin{array}{l}\text { Number } \\
\text { of participants }\end{array}$} & \multicolumn{8}{|c|}{ PPD positive } & \multirow{2}{*}{\multicolumn{2}{|c|}{ Confirmed TB }} & \multirow{3}{*}{$\begin{array}{l}\text { Number of } \\
\text { colleges } \\
\text { surveyed }\end{array}$} \\
\hline & & \multicolumn{2}{|c|}{ PPD weakly positive } & \multicolumn{2}{|c|}{ PPD moderately positive } & \multicolumn{2}{|c|}{ PPD strongly positive } & \multicolumn{2}{|l|}{$\begin{array}{l}\text { Total } \\
\text { positive }\end{array}$} & & & \\
\hline & & $\mathrm{N}$ & $\%$ & $\mathrm{~N}$ & $\%$ & $\mathrm{~N}$ & $\%$ & $\mathrm{~N}$ & $\%$ & $\mathrm{~N}$ & $/ 100,000$ & \\
\hline 2005 & 54,459 & 8,610 & 15.81 & 7,575 & 13.91 & 2,941 & 5.40 & 19,126 & 35.12 & 50 & 91.80 & 5 \\
\hline 2006 & 65,576 & 10,302 & 15.71 & 10,289 & 15.69 & 3,607 & 5.50 & 24,198 & 36.90 & 62 & 94.50 & 6 \\
\hline 2007 & 97,673 & 15,735 & 16.11 & 16,858 & 17.26 & 5,684 & 5.82 & 38,277 & 39.19 & 127 & 130.00 & 8 \\
\hline 2010 & 82,776 & 13,997 & 16.91 & 14,767 & 17.84 & 5,564 & 6.72 & 34,328 & 41.47 & 132 & 159.47 & 7 \\
\hline 2011 & 87,585 & 16,519 & 18.86 & 16,098 & 18.38 & 8,331 & 9.51 & 40,948 & 46.75 & 151 & 172.40 & 7 \\
\hline 2012 & 42,676 & 7,989 & 18.72 & 7,887 & 18.48 & 3,834 & 8.98 & 19,710 & 46.19 & 77 & 180.43 & 4 \\
\hline 2013 & 7,512 & 1,399 & 18.62 & 1,372 & 18.26 & 642 & 8.55 & 3,413 & 45.43 & 14 & 186.37 & 1 \\
\hline The total & 656,212 & 110,390 & 16.83 & 112,039 & 17.07 & 44,563 & 6.79 & 266,992 & 40.69 & 960 & 146.29 & \\
\hline
\end{tabular}

As shown in Figure 1, the rate of confirmed TB cases peaked in 2008, because a high school and a university in Zhengzhou failed to perform PPD tests in 2007, with a TB outbreak in these institutions occurring in 2008. In addition, 2013 marked the final rising trend in total number of confirmed TB cases, because only one university in Zhengzhou performed TB surveillance due to a shortage of funds. We also noticed that many colleges had not administered PPD tests for nearly two years in Henan province.

\section{PPD test results by gender and region}

A total of $41.68 \%$ males had positive PPD results, with a prevalence of 218.65/100,000. Meanwhile, 39.61\% females had positive PPD results, with a prevalence of $67.93 / 100,000$. Total positivity rate, strongly positive rate, and TB prevalence were all significantly higher in males than in females $(p<0.0001)$. Total positivity and prevalence rates in urban students were $38.03 \%$ and $80.44 / 100,000$, respectively, while rural students had rates of $42.04 \%$ and $179.80 / 100,000$, respectively. Total positivity, strongly positive, and prevalence rates were significantly higher in rural students compared with urban counterparts $(p<0.0001)$ (Table 2$)$. 
Table 2 PPD test results by gender, and residence location among study participants

\begin{tabular}{|c|c|c|c|c|c|c|c|c|c|c|c|}
\hline \multirow[t]{3}{*}{ Projects } & \multirow[t]{3}{*}{ Sample size } & \multicolumn{8}{|c|}{ Number of PPD positive (rate) } & \multirow{2}{*}{\multicolumn{2}{|c|}{$\begin{array}{l}\text { Number of confirmed } \\
\text { TB cases }\end{array}$}} \\
\hline & & \multicolumn{2}{|c|}{ PPD weakly positive } & \multicolumn{2}{|c|}{ PPD moderately positive } & \multicolumn{2}{|c|}{ PPD strongly positive } & \multicolumn{2}{|c|}{ Total positive } & & \\
\hline & & $\mathrm{N}$ & $\%$ & $\mathrm{~N}$ & $\%$ & $\mathrm{~N}$ & $\%$ & $\mathrm{~N}$ & $\%$ & $\mathrm{~N}$ & $/ 100,000$ \\
\hline Male & 341,186 & 56,777 & 16.64 & 59,672 & 17.49 & 25,754 & 7.55 & 142,203 & 41.68 & 746 & 218.65 \\
\hline female & 315,026 & 53,613 & 17.02 & 52,367 & 16.62 & 18,809 & $5.97^{\mathrm{a}}$ & 124,789 & 39.61 & 214 & $67.93^{b}$ \\
\hline The total & 656,212 & 110,390 & 16.83 & 112,039 & 17.07 & 44,563 & 6.79 & 266,992 & 40.69 & 960 & 146.29 \\
\hline Urban & 221,292 & 36,435 & 16.47 & 38,286 & 17.30 & 9,426 & 4.26 & 84,147 & 38.03 & 178 & 80.44 \\
\hline Rural & 434,920 & 73,955 & 17.00 & 73,753 & 16.96 & 35,137 & $8.08^{\mathrm{c}}$ & 182,845 & 42.04 & 782 & $179.80^{d}$ \\
\hline The total & 656,212 & 110,390 & 16.83 & 112,039 & 17.07 & 44,563 & 6.79 & 266,992 & 40.69 & 960 & 146.29 \\
\hline
\end{tabular}

Note: Compared to boys, $\mathbf{a}=537.38, P<0.001 ; \mathbf{b}=254.70, P<0.001$. Compared to rural, $\mathbf{c}=3380.17, P<0.001 ; \mathbf{d}=99.13, P<0.001$.

\section{Discussion}

This study revealed an increase in the prevalence of PPD positivity over 10 years, corroborating other reports in China $^{29,30}$, but different from the decreasing trend found in the 2010 FNTES.

College freshmen are active and mobile, increasing the risk of TB transmission. A large number of young adult TB cases constitute an obstacle to TB control ${ }^{31}$. College students undergo physical development and endocrinological changes from adolescence to adulthood, with poor dietary behaviors and less physical activity, which affect long-term health and chronic disease risk ${ }^{32}$.

The students examined had just completed the college entrance examination (CEE), with elevated stress and possibly a weakened immune system. They tended to have less sleep, lived in cramped dormitories, and studied in classrooms with inadequate air quality. Some had poor nutrition, which further contributed to immune suppression. Such factors increase the risk of contracting TB.

Students attending university are required to undergo entrance physical examination and PPD test. With PPD examinations in freshmen, TB epidemic rarely occurs. However, a senior middle school and a university in Zhengzhou in 2007 failed to perform PPD testing, and a TB outbreak occurred at the two institutions. This emphasizes the importance of TB screening in this vulnerable population.

\section{Analysis of PPD test results in boys and girls}

Total and strongly positive rates, and the prevalence of positive PPD results in study participants were significantly higher in men compared with women, as previously reported in China ${ }^{33}$. A potential factor contributing to this difference is that males frequent internet cafes more often than females; these cybercafés tend to be crowded, with poor ventilation. Another possible reason is the poorer hygiene in men's dormitories compared with women's, making TB transmission more likely. TB transmission is related to long-term close contact and a dirty living environment ${ }^{34}$. In many low- and middle-income countries women smoke less than men ${ }^{35}$, and smoking increases the risk of pulmonary tuberculosis ${ }^{36}$.

\section{Comparison of PPD test results between urban and rural students}

Our survey demonstrated that total and strongly positive PPD results, as well as TB prevalence were higher in students from rural regions than those from urban areas. Poor economic conditions and nutritional deficiencies in rural areas may lead to lower immunity. Some poor students from rural areas can only afford basic needs, and may have inadequate intake of meat, eggs, milk and fruits. Rural students may also have less knowledge regarding TB control because health education only comprises a few lectures per semester in many high schools. The lack of basic knowledge of hygiene can result in bad habits such as spitting, which increases the risk of TB transmis- 
sion. We suggest health education should be provided to students from primary school through university.

\section{Therapeutic measures for individuals with strongly positive PPD tests}

Students with strongly positive PPD results, i.e. who have latent TB infection, should be educated about the importance of treatment, and treated to prevent transmission. PPD negative students should be injected BCG vaccine for protection against TB. Strongly positive PPD test students should be immediately treated. According to WHO more than a decade ago, the most cost-effective way to stop TB in communities with high incidence is by curing it. DOTS (Directly-Observed Treatment, Short-Course) is considered the best curative method for $\mathrm{TB}^{37}$. However, some students find it difficult to conform to unaffordable TB medication with DOTS standards, and to comply with regimens in developing countries. Irregular medication use can lead to TB drug resistance. Therefore, coordinated efforts should target continuous scale-up of screening, early diagnosis, and proper treatment of TB, in line with DOTS. The ultimate goal is effective prevention and control of TB in this high risk population.

\section{Conclusion}

A TB control program includes screening, tracking (such as drugs for prophylaxis and treatment) and re-check, and any disrupted link could increase TB prevalence. Therefore, adequate human and financial resources are needed for TB control programs. Direct and indirect costs, as well as social consequences of TB can be devastating to the patient, family and community ${ }^{38,39}$. Positive PPD rates in the assessed freshmen have increased yearly during the study period. Colleges and the public health department should be aware of this trend and implement adequate measures.

The title of the research topic is "the Medical science and technology research project of Henan Province in 2014" and the research topic number is 201404053.

\section{Acknowledgements}

We acknowledge the efforts of all workers. The authors are grateful to the Department of Tuberculosis, Sixth People's Hospital of Zhengzhou for support. This study was supported by the Medical science and technology research project of Henan Province in 2014. We would like to thank Northwest A\&F University for technical help, and the Zhengzhou Railway Vocational and Technical College for financial support.

\section{Conflict of interest}

All authors declare that they have no conflict of interests.

\section{References}

1. Dahl JL, Wei J, Moulder JW, Laal S, Friedman RL. Subcellular localization of the Iitracellular survival-enhancing Eis protein of Mycobacterium tuberculosis. Infect Immun. 2001;69(7):4295-302.

2. Murray CJ, Lopez AD. Alternative projections of mortality and disability by cause 1990-2020: Global Burden of Disease Study. Lancet. 1997;349(9064):1498-504.

3. Connell DW, Berry M, Cooke G, Kon OM. Update on tuberculosis: TB in the early 21 st century. Eur Respir Rev. 2011;20(120):71-84.

4. Health Organization W. Global tuberculosis control: surveillance, planning, financing. WHO report 2006.

5. Organization WH. Global tuberculosis control 2009: epidemiology, strategy, financing. WHO Report 2009.

6. WHO. Global tuberculosis control: Global Tuberculosis Programme, WHO Report 2010.

7. WHO. Global Tuberculosis Report 2014. WHO report 2014.

8. WHO. Global Tuberculosis Report 2016. WHO report 2016.

9. Horie T, Lien LT, Tuan LA, Tuan PL, Sakurada S, Yanai $\mathrm{H}$, et al. A survey of tuberculosis prevalence in Hanoi, Vietnam. International Journal of Tuberculosis \& Lung Disease the Official Journal of the International Union Against Tuberculosis \& Lung Disease. 2007;11(5):562.

10. Telisinghe L, Fielding KL, Malden JL, Hanifa Y, Churchyard GJ, Grant AD, et al. High Tuberculosis Prevalence in a South African Prison: The Need for Routine Tuberculosis Screening. Plos One. 2014;9(1): e87262.

11. Hoa NB, Tiemersma EW, Sy DN, Nhung NV, Gebhard A, Borgdorff MW, et al. Household expenditure and tuberculosis prevalence in VietNam: prediction by a set of household indicators. International Journal of Tuberculosis \& Lung Disease the Official Journal of the International Union Against Tuberculosis \& Lung Disease. 2011;15(1):32-7. 
12. Hoa NB,Sy DN, Nhung NV, Tiemersma EW, Borgdorff MW, Cobelens FG. National survey of tuberculosis prevalence in Viet Nam. Bulletin of the World Health Organization. 2010;88(4):273-80.

13. Onozaki I, Law I, Sismanidis C, Zignol M, Glaziou P, Floyd K. National TB prevalence surveys in Asia, 19902012: An overview of results and lessons learned. Tropical Medicine \& International Health Tm \& Ih. 2015;20(9):1128. 14. Narain R, Geser A, Jambunathan MV, Subramanian M. Some aspects of a tuberculosis prevalence survey in a south indian district. Bulletin of the World Health Organization. $1963 ; 29(5): 641$.

15. TE T, S R, AB R, ML P, MI Q, VM C, et al. The 1997 Nationwide Tuberculosis Prevalence Survey in the Philippines. Int J Tuberc Lung Dis. 1999;3(3):471-7.

16. Kebede AH, Alebachew Z, Tsegaye F, Lemma E, Abebe A, Agonafir M, et al. The first population-based national tuberculosis prevalence survey in Ethiopia, 20102011. International Journal of Tuberculosis \& Lung Disease the Official Journal of the International Union Against Tuberculosis \& Lung Disease. 2014;18(6):635-9.

17. Tupasi TE. The power of knowledge to effect change: the 1997 Philippines nationwide tuberculosis prevalence survey. International Journal of Tuberculosis \& Lung Disease the Official Journal of the International Union Against Tuberculosis \& Lung Disease. 2000;4(10):990.

18. Hong YP, Kim SJ, Lew WJ, Lee EK, Han YC. The seventh nationwide tuberculosis prevalence survey in Korea, 1995. International Journal of Tuberculosis \& Lung Disease the Official Journal of the International Union Against Tuberculosis \& LungDisease. 1993;74(5):323-31.

19. Wang L, Zhang H, Ruan Y, Chin DP, Xia Y, Cheng S, et al. Tuberculosis prevalence in China, 1990-2010; a longitudinal analysis of national survey data. Lancet. 2014;383(9934):2057-64.

20. Tabuchi T, Takatorige T, Hirayama Y, Nakata N, Harihara S, Shimouchi A, et al. Tuberculosis infection among homeless persons and caregivers in a high-tuberculosis-prevalence area in Japan: a cross-sectional study. Bmo Infectious Diseases. 2011;11(1):1-8.

21. Zumla A, George A, Sharma V, Herbert RHN, Oxley A, Oliver M. The WHO 2014 Global tuberculosis report-further to go. Lancet Glob Health. 2015;3(1): e10-e2. 22. Lopez AD, Mathers CD, Ezzati M, Jamison DT, Murray CJL. Global burden of disease and risk factors: World Bank and Oxford University Press; 2006.
23. Floyd K, Pantoja A. Financial resources required for tuberculosis control to achieve global targets set for 2015. Bull World Health Organ. 2008;86(7):568-76.

24. Lonnroth K, Castro KG, Chakaya JM, Chauhan LS, Floyd K, Glaziou P, et al. Tuberculosis control and elimination 2010-50: cure, care, and social development. Lancet. 2010;375(9728):1814-29.

25 . Dye C. India's leading role in tuberculosis epidemiology \& control. Indian J Med Res. 2006;123(4):481-4.

26. Wang LX, Cheng SM, Chen MT. The fifth national tuberculosis epidemiological survey in 2010. Chinese Journal of Antituberc. 2012;8:485-95.

27. Adults and children. Diagnostic Standards and Classification of Tuberculosis in Adults and Children. This official statement of the American Thoracic Society and the Centers for Disease Control and Prevention was adopted by the ATS Board of Directors, July 1999. This statement was endorsed by the Council of the Infectious Disease Society of America, September 1999. Am J Respir Crit Care Med. 2000;161(4 Pt 1):1376-95.

28. Wang JY. Internal medicine. Beijing: People's medical publishing house; 2002.

29. Huang RR, Wang H, Wang Y, Xiao X, Zeng H, Zhang $\mathrm{Z}$, et al. Requirement analysis on tuberculosis prevention and treatment knowledge for middle school students in three gorges reservoir areas in Chongqing. Chinese Journal of School Health. 2009;30(1):6-7.

30. Wang L, Wu LM, Wang K, Lu M, Wang M, Li QC. Study on the automatic school tuberculosis early-warning system based on geographic information system. Chinese Journal of School Health. 2012;33(1):33-5.

31. Dye C, Williams BG. The population dynamics and control of tuberculosis. Science. 2010;328(5980):856-61.

32. Small M, Bailey-Davis L, Morgan N, Maggs J. Changes in eating and physical activity behaviors across seven semesters of college: living on or off campus matters. Health Educ Behav. 2013;40(4):435-41.

33. Zhou BB, Lu HC, Gong DG. Epidemiological characteristic of student cases with pulmonary tuberculosis in Yinzhou district of Ningbo city 2005-2009. Chinese Journal of School Health. 2011;32(5):599-60.

34. Promtussananon S, Peltzer K. Perceptions of tuberculosis: attributions of cause, suggested means of risk reduction, and preferred treatment in the Limpopo province, South Africa. J Health Popul Nutr. 2005;23(1):74-81. 35. Hitchman SC, Fong GT. Gender empowerment and 
female-to-male smoking prevalence ratios. Bull World Health Organ. 2011;89(3):195-202.

36. Gupta D, Agarwal A, Kumar S, Jindal S. Smoking increases risk of pulmonary tuberculosis. 2001. 65-70 p. 37. WHO. Treatment of tuberculosis: guidelines for national programmes. $3^{\text {rd }}$ ed. WHO. 1997:220.
38. Hanson C, Floyd K, Weil D. Reichman and Hershfield's Tuberculosis, Chapter 45, Tuberculosis in the poverty alleviation agenda. CRC Press; 2006. p. 1097-114.

39. Migliori GB, D'Ambrosio L, Centis R. Tuberculosis: an ancient and evergreen disease. Eur Respir Rev. 2011;20(120):69-70. 